\title{
Glycaemic control for people with type 2 diabetes in Saudi Arabia - an urgent need for a review of management plan
}

\author{
Mohammed J. Alramadan', Dianna J. Magliano ${ }^{1,2}$, Turky H. Almigbal ${ }^{3}$, Mohammed Ali Batais ${ }^{3}$, Afsana Afroz ${ }^{1}$, \\ Hesham J. Alramadhan ${ }^{4}$, Waad Faozi Mahfoud ${ }^{5}$, Adel Mehmas Alragas ${ }^{6}$ and Baki Billah ${ }^{1 *}$
}

\begin{abstract}
Background: The aim of this study was to assess inadequate glycaemic control and its associated factors among people with type 2 diabetes in Saudi Arabia.

Methods: A cross-sectional study design was used. Adults with type 2 diabetes attending diabetes centres in Riyadh, Hofuf and Jeddah cities were interviewed and their anthropometrics were measured. Their medical records were also reviewed to collect information related to recent lab tests, medications, and documented comorbidities. Multivariable logistic regression were used for data analysis.

Results: A total of 1111 participants were recruited in the study. Mean age was $57.6( \pm 11.1)$ years, $65.2 \%$ of the participants were females, and mean $\mathrm{HbA} 1 \mathrm{c}$ was $8.5 \pm 1.9 \%$. About three-fourths of participants had inadequate glycaemic control ( $\geq 7 \%$ ). Multivariable analysis showed that age $\leq 60$ years, longer duration of diabetes, living in a remote location, low household income, low intake of fruits and vegetable, low level of physical activity, lack of knowledge about haemoglobin A1c, high waist-hip ratio, low adherence to medication, and using injectable medications were independent risk factors for inadequate glycaemic control.

Conclusions: Inadequate glycaemic control is prevalent among people with type 2 diabetes in Saudi Arabia. In order to improve glycaemic control diabetes management plan should aim at controlling the modifiable risk factors which include low intake of fruits and vegetable, low level of physical activity, lack of knowledge about haemoglobin A1c, high waist-hip ratio, and low adherence to medications.
\end{abstract}

Keywords: Saudi Arabia, Diabetes, Glycaemic control

\section{Background}

Diabetes mellitus is a major worldwide public health issue. A recent study showed that the prevalence of diabetes mellitus in Saudi Arabia was 13.4\% [1], which is higher than the global prevalence of $8.8 \%$ and the prevalence in the Middle East of $10.7 \%$ [2]. In fact, Saudi Arabia is among the countries with the highest prevalence of diabetes regionally and globally [2], and the prevalence of diabetes in the country is on the rise [3].

The primary goal of the management of diabetes is to maintain blood glucose levels within or close to normal

\footnotetext{
* Correspondence: baki.billah@monash.edu

${ }^{1}$ Department of Epidemiology and Preventive Medicine, School of Public Health and Preventive Medicine, Monash University, Melbourne, Australia Full list of author information is available at the end of the article
}

ranges [4]. It is well established that elevated blood glucose level increases the risk of diabetes complications and mortality $[5,6]$, while intensive glycaemic control substantially lower the risk [7, 8]. Unfortunately, studies from Saudi Arabia showed that half to two-thirds of people with type 2 diabetes mellitus (T2DM) have poor glycaemic control [9-13], and the prevalence of diabetes complications is higher than the global and regional prevalence [14-16].

A few studies have examined risk factors of poor glycaemic control among people with T2DM in Saudi Arabia $[9,10,12,13,17]$. Many of these studies were limited to a small geographical location and included a relatively small cohort of participants. In addition, some of these studies used random or fasting blood sugar test

(c) The Author(s). 2018 Open Access This article is distributed under the terms of the Creative Commons Attribution 4.0 International License (http://creativecommons.org/licenses/by/4.0/), which permits unrestricted use, distribution, and reproduction in any medium, provided you give appropriate credit to the original author(s) and the source, provide a link to the Creative Commons license, and indicate if changes were made. The Creative Commons Public Domain Dedication waiver (http://creativecommons.org/publicdomain/zero/1.0/) applies to the data made available in this article, unless otherwise stated. 
to assess glycaemic control which is not as accurate as the glycated haemoglobin A1c (HbA1c) level that measures the control over a number of weeks [4]. Moreover, not all potential risk factors of poor control were explored in the previous studies. A systematic review and meta-analysis showed that among other factors, diet and physical activity were significantly associated with glycaemic control [18]. Studies from Saudi Arabia, however, did not adequately explore the effect of physical activity and eating habits.

To achieve glycaemic control goals among people with T2DM, all possible associated risk factors of inadequate control must be identified and considered in the management. The aim of this study was to assess the current status of glycaemic control and to identify risk factors for inadequate control among people with T2DM in Saudi Arabia.

\section{Methods}

This study was conducted as a part of a research project that examined the status of glycaemic control, diabetes complications and quality of life for people with T2DM in Saudi Arabia. The study methodology has been described in detail in another article [19]. Ethical approval was obtained from the Monash University Human Research Ethics Committee in Australia and the Research Ethics Committee of the Ministry of Health in Saudi Arabia. All the study procedures were carried out in accordance with the principles of the Declaration of Helsinki as revised in 2013.

\section{Participants}

The study population were people with T2DM aged 18 years and over who were followed up at diabetes centres in three major cities (Hofuf, Riyadh, and Jeddah) in Saudi Arabia. The plan was to recruit 1082 participants based on a sample size calculation with $90 \%$ power, $5 \%$ significance level, a margin of error of $2.5 \%$, and a prevalence of poor glycaemic control of 50\% [9, 20]. Inclusion criteria include documented diagnosis of T2DM, aged 18 years and above, and duration of diabetes of at least 1 year. Pregnant women and participants who did not have a HbA1c test within 1 year were excluded.

\section{Data collection}

Participants were selected randomly from consecutive attendees of the diabetic centres between May 15 and November 30, 2017. After explaining the study and obtaining informed consent in writing, participants were interviewed using a pre-tested structured electronic questionnaire through Research Electronic Data Capture (REDCap) application [19, 21]. The questionnaire collects information related to socio-demographics, lifestyle, medical history, cognitive function, anxiety and depression. Socio-demographic data include gender, date of birth, marital status, education, and income. Lifestyle data include smoking status, physical activity (Global Physical Activity Questionnaire (GPAQ) [22]), and dietary habits. The dietary habit section included 10 questions selected from the UK diabetes and diet questionnaire (UKDDQ) [23] with some modifications to make some points more suitable for the eating habits of the Saudi population. The dietary questions include the frequency of consuming fruits, vegetables, red meat, desserts, date, sugary drinks, butter, bread, and rice and the fat content of consumed milk. The dietary habit variable was measured as a scale between zero and 48 , where high score means the individual is following healthy eating habits. Medical history data include the duration of diabetes, modality of treatment, follow-up centre, other comorbidities, medication adherence (the 4-item Morisky Medication Adherence questionnaire) [24], family support in regards to diet and physical activity, and peripheral neuropathy (the Michigan Neuropathy Screening Instrument) [25]. Mental status data include anxiety (Generalized Anxiety Disorder Scale (GAD-2)) [26], depression (the Patient Health Questionnaire-2 (PHQ-2)) [27], and cognitive function (Rowland Universal Dementia Assessment Scale (RUDAS)) [28]. The establishers' permission to use the above-mentioned tools was obtained.

After interviewing participants, their anthropometrics were measured and recorded. Blood pressure was measured three times after sitting for at least $10 \mathrm{~min}$ using the Omron BP742N5 Series Upper Arm Blood Pressure Monitor with a cuff that fits standard and large arms. Weight was measured after instructing participants to remove their shoes and outer layers of clothing. Height, waist circumference, and hip circumference were measured twice and if the measurement varied by more than $2 \mathrm{~cm}$, a third measurement was taken. Waist and hip circumference were measured against thin clothing. Participants' medical records were reviewed for most recent lab test results, namely HbA1c, creatinine, cholesterol, high density lipoprotein (HDL), low density lipoprotein (LDL), and triglycerides. Information regarding currently prescribed medication, and documented diagnosis of hypertension, coronary artery disease, retinopathy, and stroke was also collected from medical records.

\section{Operational definitions}

Glycaemic control was categorised into controlled $(\mathrm{HbA} 1 \mathrm{c}<53 \mathrm{mmol} / \mathrm{mol}(<7 \%))$, partially controlled (HbA1c $53-63 \mathrm{mmol} / \mathrm{mol}(7 \%$ to $<8 \%)$ ), and poorly controlled $(\mathrm{HbA} 1 \mathrm{C} \geq 64 \mathrm{mmol} / \mathrm{mol}(\geq 8 \%)$ [4]. A HbAlc cut-off value of $>68 \mathrm{mmol} / \mathrm{mol}(\geq 9 \%)$ was also used to represent very poor control [29]. Using the Global Physical Activity Questionnaire (GPAQ) [22], the total number 
of minutes of physical activity per week was categorised into $\geq 150 \mathrm{~min}$ and $<150 \mathrm{~min}$ [4]. Treatment modalities was categorized as oral tablets only, injectable medications (insulin and glucagon-like peptide-1 receptor agonists) only, and combined (oral tablets and injectable medications). Using the Morisky Medication Adherence questionnaire [24] medication adherence was categorized into adequate (a score of zero), and inadequate (a score of one or more). Hypoglycaemia was defined as episodes of mild or severe hypoglycaemia symptoms including hunger sweating, light headedness, headache, shaking, trembling, weakness, dizziness, confusion, loss of consciousness, and seizures. Family support in regards to healthy diet and physical activity was categorised as good support if healthy diet and physical activity were encouraged all the time, inadequate support if encouragement was sometimes, and poor support if family members rarely or never encouraged healthy diet or physical activity. Participants were considered unaware of HbA1c if they had not heard of HbA1c before or they did not know the recommended HbA1c target for people with diabetes. Body Mass Index (BMI) was categorised according to the current World Health Organization guidelines into normal $\left(<25.0 \mathrm{~kg} / \mathrm{m}^{2}\right)$, pre-obesity $\left(25.0-29.9 \mathrm{~kg} / \mathrm{m}^{2}\right.$ ), and obesity (class I, II and II $\geq 30.0 \mathrm{~kg} / \mathrm{m}^{2}$ ). High waist-hip ratio was defined as a ratio of $>0.96$ for men and $>0.98$ for women [30]. Hypertension was defined as either a documented diagnosis of hypertension, taking antihypertension medications, or three previous high blood pressure readings (systolic $\geq 140$ or diastolic $\geq 90$ ) [4]. Dyslipidaemia was defined as any of the following: total cholesterol $>4.0 \mathrm{mmol} / \mathrm{L}$ $(154.7 \mathrm{mg} / \mathrm{dl}), \mathrm{LDL}>2.0 \mathrm{mmol} / \mathrm{L}(77.3 \mathrm{mg} / \mathrm{dl})$, triglycerides $>2.0 \mathrm{mmol} / \mathrm{L}(177.1 \mathrm{mg} / \mathrm{dl})$, or $\mathrm{HDL}<1.0 \mathrm{mmol} / \mathrm{L}$ $(38.7 \mathrm{mg} / \mathrm{dl})$ [31]. Impaired cognitive function was defined as a score of $\leq 22$ in the Rowland Universal Dementia Assessment Scale (RUDAS) [28]. Depression was defined as a score of three and more using the Patient Health Questionnaire-2 (PHQ-2)) [27]. Anxiety was defined as a score of three and more using the Generalized Anxiety Disorder Scale (GAD-2)) [26]. Macrovascular complications were defined as having one of the following: documented diagnosis of stroke (irreversible cerebrovascular accident), documented diagnosis of coronary artery disease, taking medication for coronary artery disease, underwent a procedure for coronary artery disease, or self-reported lower extremity ulcers or amputations. Microvascular complication was defined as having one of the following: documented diagnosis of retinopathy, the participant had been told by an ophthalmologist that he or she had retinopathy, a score of seven or more using the Michigan Neuropathy Screening Instrument [25], or estimated glomerular filtration rate $\leq 60 \mathrm{ml} / \mathrm{min} / 1.73 \mathrm{~m}^{2}$ calculated from serum creatinine using the Chronic Kidney Disease Epidemiology Collaboration (CKD-EPI) equation [32, 33].

\section{Data analysis}

Stata SE version 15.0 was used for data analysis. Data were summarised and presented as a mean $( \pm$ standard deviation) for numerical data and frequency and percentage for categorical data. ANOVA and chi-square tests were used to examine univariate associations between risk factors and levels of glycaemic control. Potential risk factors with a $p$-value of 0.2 from univariate analysis were entered into multivariable logistic regression with step wise variable selection [34]. In the regression analysis, glycaemic control was categorised into controlled (HbAlc $<53 \mathrm{mmol} / \mathrm{mol}$ $(<7 \%)$ and inadequately controlled (HbA1c $\geq 53 \mathrm{mmol} /$ mol $(\geq 7 \%))$. The determinants were also examined for very poor glycaemic control $(\mathrm{HbA} 1 \mathrm{c}>68 \mathrm{mmol} / \mathrm{mol}$ $(\geq 9 \%))$. A $p$-value of 0.05 or less was considered as statistical significant.

\section{Results}

A total of 1111 participants were recruited in this study; 624 participants (56.2\%) were from Riyadh, 239 (21.5\%) were from Hofuf, and 248 (22.3\%) were from Jeddah. Four hundred and-fifty participants (40.5\%) were followed up at diabetes centres only, while 125 participants (11.3\%) were followed up at both diabetes centres and hospitals and 535 participants (48.2\%) were followed up at both diabetes centres and primary healthcare centres. Mean age was $57.6( \pm 11.1)$ years, mean duration of diabetes was $13.9( \pm 8.4)$ years, and $65.2 \%(724)$ of the participants were females, while $34.8 \%$ (387) were males. Mean body mass index was $32.9( \pm 8.1) \mathrm{kg} / \mathrm{m}^{2}$. Mean HbA1c was $69.4( \pm 15.5) \mathrm{mmol} / \mathrm{mol}(8.5 \%( \pm 1.9 \%))$, and $24.1 \%$ of participants had good glycaemic control $(\mathrm{HbA} 1 \mathrm{c}<53 \mathrm{mmol} / \mathrm{mol}(<7 \%)), 21.7 \%$ had partial control (HbA1c 53-63 mmol/mol (7-7.9\%)), and $54.2 \%$ had poor control $(\mathrm{HbA} 1 \mathrm{C} \geq 64 \mathrm{mmol} / \mathrm{mol}(\geq 8 \%))$. None of the study participants were on insulin pump or continuous glucose monitoring.

Table 1 summarises participants' demographic and lifestyle characteristics by different levels of glycaemic control. There was a higher prevalence of poor glycaemic control among those with lower levels of education ( $p$-value: $<0.001)$, living in a remote place ( $p$-value: 0.002$)$, and not working including house-wives ( $p$-value: 0.005$)$. A higher proportion of those aged 60 years and younger had poor glycaemic control, however, the association was not statistically significant in univariate analysis. Similarly, gender, nationality, household income, and region were not significantly related to glycaemic control. Regarding lifestyle factors, there was no difference in the mean of healthy eating habit score among different categories of glycaemic control. However, higher proportions of those with less than daily intake of fruits and vegetables had poor glycaemic control ( $p$-value: 0.011$)$. Similarly, higher proportions of those with physical activity less than 
Table 1 Demographic and lifestyle characteristics by level of glycaemic control

\begin{tabular}{|c|c|c|c|c|}
\hline \multirow[t]{2}{*}{ Variable } & \multicolumn{3}{|l|}{ Glycaemic control } & \multirow[t]{2}{*}{$P$-value } \\
\hline & $\begin{array}{l}\text { Good (HbA1c }<7.0 \%) \\
n=263\end{array}$ & $\begin{array}{l}\text { Partial (HbA1c } 7.0 \%-7.9) \\
n=237\end{array}$ & $\begin{array}{l}\text { Poor }(\mathrm{HbA} 1 \mathrm{c} \geq 8 \%) \\
n=592\end{array}$ & \\
\hline \multicolumn{5}{|l|}{ Age \% (n) } \\
\hline$>60$ years & 28.4 (109) & $22.4(86)$ & $49.2(189)$ & \multirow[t]{3}{*}{0.106} \\
\hline $46-60$ years & $21.4(123)$ & $21.6(124)$ & $57.0(327)$ & \\
\hline$<46$ years & $23.1(31)$ & $20.2(27)$ & $56.7(76)$ & \\
\hline \multicolumn{5}{|l|}{ Gender: female \% (n) } \\
\hline Female & $22.9(162)$ & $20.9(148)$ & $56.3(399)$ & \multirow[t]{2}{*}{0.173} \\
\hline Male & $26.4(101)$ & $23.2(89)$ & $50.4(193)$ & \\
\hline \multicolumn{5}{|l|}{ Nationality \% (n) } \\
\hline Saudi & $23.6(246)$ & $21.7(226)$ & $54.7(570)$ & \multirow[t]{2}{*}{0.207} \\
\hline Non-Saudi & $34.0(17)$ & $22.0(11)$ & $44.0(22)$ & \\
\hline \multicolumn{5}{|l|}{ Education level \% (n) } \\
\hline University/college & $30.9(60)$ & $28.9(56)$ & $40.2(78)$ & \multirow[t]{2}{*}{$<0.001$} \\
\hline Lower education level & $22.6(203)$ & $20.2(181)$ & $57.2(514)$ & \\
\hline \multicolumn{5}{|l|}{ Location of residency \% (n) } \\
\hline Urban & $24.3(229)$ & $22.9(216)$ & $52.8(497)$ & \multirow[t]{3}{*}{0.002} \\
\hline Rural & $30.4(28)$ & $15.2(14)$ & $54.4(50)$ & \\
\hline Remote & $10.3(6)$ & $12.1(7)$ & $77.6(45)$ & \\
\hline \multicolumn{5}{|l|}{ Working status \% (n) } \\
\hline Working & $23.9(55)$ & $20.4(47)$ & 55.7 (128) & \multirow[t]{3}{*}{0.005} \\
\hline Not working / house-wife & $21.6(141)$ & $21.0(137)$ & $57.4(374)$ & \\
\hline Retired & $31.9(67)$ & $25.2(53)$ & $42.9(90)$ & \\
\hline \multicolumn{5}{|l|}{ Household income \% (n) } \\
\hline$\geq 6001$ SAR & $25.2(148)$ & 23.7 (139) & $51.1(300)$ & \multirow[t]{2}{*}{0.074} \\
\hline$<6001$ SAR & $22.8(115)$ & $19.4(98)$ & $57.8(292)$ & \\
\hline \multicolumn{5}{|l|}{ Region \% (n) } \\
\hline Riyadh & $26.4(161)$ & $22.5(137)$ & $51.1(311)$ & \multirow[t]{3}{*}{0.125} \\
\hline Jeddah & $22.7(56)$ & $21.5(53)$ & $55.9(138)$ & \\
\hline Hofuf & $19.5(46)$ & $19.9(47)$ & $60.6(143)$ & \\
\hline \multicolumn{5}{|l|}{ Active smoking \% (n) } \\
\hline Never & $24.6(230)$ & $21.9(205)$ & $53.5(501)$ & \multirow[t]{3}{*}{0.563} \\
\hline In the past (> 1 year) & 20.7 (19) & $17.4(16)$ & $62.0(57)$ & \\
\hline Current smoker & $22.2(14)$ & $25.4(16)$ & $52.4(33)$ & \\
\hline Eating habit score (mean $\pm S D)$ & $30.2 \pm 4.4$ & $29.6 \pm 5.1$ & $29.8 \pm 5.1$ & 0.451 \\
\hline \multicolumn{5}{|l|}{ Fruits and vegetables \% (n) } \\
\hline Daily & $31.3(76)$ & $20.2(49)$ & $48.6(118)$ & \multirow[t]{2}{*}{0.011} \\
\hline Less frequent & $21.9(186)$ & $22.2(188)$ & $55.9(474)$ & \\
\hline \multicolumn{5}{|l|}{ Physical Activity \% (n) } \\
\hline$\geq 150 \mathrm{~min} /$ week & $29.0(94)$ & $21.9(71)$ & $49.1(159)$ & \multirow[t]{2}{*}{0.032} \\
\hline$<150 \mathrm{~min} /$ week & $22.0(169)$ & $21.6(166)$ & $56.4(433)$ & \\
\hline Sitting hours (mean $\pm \mathrm{SD}$ ) & $6.1 \pm 3.6$ & $5.8 \pm 3.5$ & $6.2 \pm 3.8$ & 0.380 \\
\hline
\end{tabular}


150 min per week had poor control (p-value: 0.032). Mean number of sitting hours and smoking did not differ significantly among the categories of glycaemic control.

The association between various clinical characteristics and glycaemic control are presented in Table 2. Higher proportions of poor control were among people with longer duration of diabetes ( $p$-value: $<0.001)$, and who were taking injectable medications ( $p$-value: $<0.001$ ), followed up mainly at primary health care or diabetes centres ( $p$-value: 0.019$)$, used glucometer twice or more a week ( $p$-value: 0.017 ), and were not aware of HbA1c or the recommended HbA1c target for people with diabetes ( $p$-value: 0.016). Similarly, higher proportions of poor control were among those who had less frequent hypoglycaemia events ( $p$-value: 0.016), macrovascular complications ( $p$-value: 0.019$)$, microvascular complications ( $p$-value $<0.001)$, and high waist-hip ratio ( $p$-value: $0.001)$. Other clinical characteristics including family history of diabetes, family support, hypertension, adherence to medication, depression, anxiety, cognitive function, dyslipidaemia, and body mass index, did not appear to have an association with glycaemic control.

Figure 1 summarises the results of the multivariable logistic regression analysis. A total of 379 participants (34.1\%) had very poor glycaemic control $(\mathrm{HbA} 1 \mathrm{c}>68 \mathrm{mmol} / \mathrm{mol}(>9 \%))$. Less than daily intake of fruits and vegetables increased the risk of inadequate and very poor control by $60 \%$ and $79 \%$ respectively. Low level of physical activity was associated with $48 \%$ and $62 \%$ higher risk of inadequate and very poor control respectively. Inadequate knowledge of $\mathrm{HbA1c}$ was associated with 1.9-fold and 2.5-fold higher risk of inadequate and very poor control respectively. High waist-hip ratio increased the risk of very poor control by $72 \%$, while frequent episodes of hypoglycaemia is associated with lower risk of both inadequate and very poor control. Other risk factors that were associated with inadequate and very poor control include younger age, longer duration of diabetes, remote location of residence, and using injectable medications with or without oral tablets.

Figure 2 illustrates the adjusted association between risk factors and inadequate control (HbA1c $\geq 7 \%)$ for people who were on oral tablets only as well as for those on injectable medications (with or without oral tablets). Among people on oral tablets the risk of inadequate control was higher by: $56 \%$ for low intake of fruits and vegetables, $50 \%$ for high waist-hip ratio, and by $55 \%$ for inadequate adherence to medication. Inadequate knowledge of HbA1c was associated with 2.1-fold increased risk among those on oral tablets, while frequent hypoglycaemia reduced the risk by $58 \%$. Other risk factors of inadequate control among those on oral tablets include younger age and longer diabetes duration. For participants who were on injectable medications, low level of physical activity increased the risk of inadequate control by 2.1 -folds, while high waist-hip ratio reduced the risk by $61 \%$. Other risk factors of inadequate control among those on injectable medications were lower household income and followed up mainly at diabetes centres, while people from Jeddah appeared to have lower risk.

\section{Discussion}

In this current multi-centre study we have assessed the status of glycaemic control and its associated factors among people with T2DM attending diabetes centres in Saudi Arabia. One important finding was that only $24.1 \%$ of people with T2DM achieved the recommended HbA1c level of less than $<53 \mathrm{mmol} / \mathrm{mol}(<7 \%)$, while the majority $(75.9 \%)$ did not attained this target. Our findings, however, were comparable to the findings of recent studies from Saudi Arabia and other Arabian Gulf Countries [10-13, 35-39]. Despite quality health care services and various antidiabetic medications that are available for people with diabetes at no cost, the majority of people with T2DM in Saudi Arabia continue to have inadequate glycaemic control. A possible explanation could be the embracing of unhealthy lifestyle.

Sedentary lifestyle and the consumptions of processed, energy condensed, and fat-rich food have led to the increased prevalence of obesity and diabetes, and have made it difficult for people with diabetes to control their blood sugar. Recent studies showed that more than half of the Saudi population consumed less than one serving of fruits and vegetables per day [40], and $96.1 \%$ of them were physically inactive [41]. Furthermore, $51.0 \%$ of the adult Saudi population were either overweight or obese [42] and the prevalence of overweight and obesity among people with diabetes was significantly higher than the general population in the country [43, 44]. In addition, studies from Saudi Arabia found an association between low physical activity and poor glycaemic control [10, 13, 35], while a study from Bahrain [45], a country that shares boundaries and similar culture with Saudi Arabia, showed an association between unhealthy eating habits and higher HbA1c among people with T2DM.

Healthy eating habits and regular physical activity are key components in the management of T2DM. The current guidelines for people with diabetes recommend 8-10 servings of fruits and vegetables every day [4]. A serving of fruits is equal to a medium-size apple, orange, or banana, while a serving of vegetables is half a cup of corn, carrot or leafy vegetables. The guidelines also recommend at least $150 \mathrm{~min}$ of moderate to vigorous intensity physical activity per week [4]. The majority $(77.5 \%)$ of participants in this study, however, did not eat fruits and vegetables daily, which has increased their risk of 
Table 2 Clinical characteristics by level of glycaemic control

\begin{tabular}{|c|c|c|c|c|}
\hline \multirow[t]{2}{*}{ Variable } & \multicolumn{3}{|l|}{ Glycaemic control } & \multirow[t]{2}{*}{$P$-value } \\
\hline & $\begin{array}{l}\text { Good (HbA1c }<7.0 \%) \\
n=263\end{array}$ & $\begin{array}{l}\text { Partial (HbA1c } 7.0 \%-7.9) \\
n=237\end{array}$ & $\begin{array}{l}\text { Poor (HbA1c } \geq 8 \%) \\
n=592\end{array}$ & \\
\hline \multicolumn{5}{|l|}{ Diabetes Duration \% (n) } \\
\hline$\leq 10$ years & $34.7(143)$ & $25.5(105)$ & $39.8(164)$ & \multirow[t]{2}{*}{$<0.001$} \\
\hline$>10$ years & 17.5 (119) & $19.4(132)$ & $63.0(428)$ & \\
\hline \multicolumn{5}{|l|}{ Family history of diabetes \% ( $\mathrm{n}$ ) } \\
\hline Yes & $22.9(187)$ & $22.2(181)$ & $54.9(447)$ & \multirow[t]{2}{*}{0.325} \\
\hline No & $27.2(75)$ & $20.3(56)$ & $52.5(145)$ & \\
\hline \multicolumn{5}{|l|}{ Modality of treatment } \\
\hline Oral tablets & 36.4 (219) & $25.8(155)$ & $37.9(228)$ & \multirow[t]{3}{*}{$<0.001$} \\
\hline Injectable & $9.9(22)$ & $18.5(41)$ & $71.6(159)$ & \\
\hline Oral and injectable & $7.9(21)$ & $15.4(41)$ & $76.8(205)$ & \\
\hline \multicolumn{5}{|l|}{ Main follow up centre \% (n) } \\
\hline Hospital & $34.2(42)$ & $22.0(27)$ & $43.9(54)$ & \multirow[t]{3}{*}{0.019} \\
\hline Primary care centre & $24(125)$ & $23.0(120)$ & $53.0(276)$ & \\
\hline Diabetes centre & $21.3(95)$ & $20.1(90)$ & $58.6(262)$ & \\
\hline \multicolumn{5}{|l|}{ Glucometer use \% (n) } \\
\hline Once or more a week & $21.4(145)$ & $21.7(147)$ & $57.0(387)$ & \multirow[t]{2}{*}{0.017} \\
\hline Less than once a week & $28.6(118)$ & $21.8(90)$ & $49.6(205)$ & \\
\hline \multicolumn{5}{|l|}{ Hypoglycaemia events \% (n) } \\
\hline None & $26.9(170)$ & $21.1(133)$ & $52.0(328)$ & \multirow[t]{3}{*}{0.016} \\
\hline $1-5$ times & $18.2(71)$ & $22.8(89)$ & $59.1(231)$ & \\
\hline 6 times and more & $30.4(21)$ & $21.7(15)$ & $47.8(33)$ & \\
\hline \multicolumn{5}{|l|}{ Medication adherence \% (n) } \\
\hline Adequate & $26.0(165)$ & $22.4(142)$ & $51.7(328)$ & \multirow[t]{2}{*}{0.110} \\
\hline Inadequate & $21.4(98)$ & $20.8(95)$ & $57.8(264)$ & \\
\hline \multicolumn{5}{|l|}{ Family support with diet \% (n) } \\
\hline Good & $23.5(103)$ & $22.2(97)$ & $54.3(238)$ & \multirow[t]{3}{*}{0.621} \\
\hline Inadequate & $23.0(73)$ & $23.9(76)$ & $53.1(169)$ & \\
\hline Poor & $25.9(87)$ & $19.1(64)$ & $55.1(185)$ & \\
\hline \multicolumn{5}{|c|}{ Family support with physical activity \% (n) } \\
\hline Good & $21.4(66)$ & $21.0(65)$ & $57.6(178)$ & \multirow[t]{3}{*}{0.460} \\
\hline Inadequate & $23.2(74)$ & $23.2(74)$ & $53.6(171)$ & \\
\hline Poor & $26.5(123)$ & $21.1(98)$ & $52.4(243)$ & \\
\hline \multicolumn{5}{|l|}{ knowledge about HbA1c \% (n) } \\
\hline Aware & $29.5(103)$ & $20.3(71)$ & $50.1(175)$ & \multirow[t]{2}{*}{0.016} \\
\hline Not aware & $21.5(160)$ & $22.3(166)$ & $56.1(417)$ & \\
\hline \multicolumn{5}{|l|}{ Body mass index \% (n) } \\
\hline Underweight/normal & $22.7(25)$ & $20.9(23)$ & $56.4(62)$ & \multirow[t]{3}{*}{0.075} \\
\hline Pre-obesity & $26.4(78)$ & $26.4(78)$ & $47.1(139)$ & \\
\hline Obesity (class I - III) & $23.3(158)$ & $20.0(136)$ & $56.7(385)$ & \\
\hline Waist-hip ratio \% (n) & & & & \\
\hline Normal & $26.4(144)$ & $24.8(135)$ & $48.8(266)$ & 0.001 \\
\hline High (male: $>0.96$, female: $>0.98$ ) & $22.1(96)$ & $17.5(76)$ & $60.5(263)$ & \\
\hline
\end{tabular}


Table 2 Clinical characteristics by level of glycaemic control (Continued)

\begin{tabular}{|c|c|c|c|c|}
\hline \multirow[t]{2}{*}{ Variable } & \multicolumn{3}{|l|}{ Glycaemic control } & \multirow[t]{2}{*}{$P$-value } \\
\hline & $\begin{array}{l}\text { Good (HbA1c }<7.0 \%) \\
n=263\end{array}$ & $\begin{array}{l}\text { Partial (HbA1c } 7.0 \%-7.9) \\
n=237\end{array}$ & $\begin{array}{l}\text { Poor (HbA1c } \geq 8 \%) \\
n=592\end{array}$ & \\
\hline \multicolumn{5}{|c|}{ Depression \% (n) } \\
\hline No & $24.1(220)$ & $22.3(203)$ & $53.6(489)$ & \multirow[t]{2}{*}{0.563} \\
\hline Yes & $23.9(43)$ & $18.9(34)$ & $57.2(103)$ & \\
\hline \multicolumn{5}{|l|}{ Anxiety \% (n) } \\
\hline No & $24.2(224)$ & $22.4(207)$ & $53.4(493)$ & \multirow[t]{2}{*}{0.328} \\
\hline Yes & $23.2(39)$ & $17.9(30)$ & 58.9 (99) & \\
\hline \multicolumn{5}{|c|}{ Cognitive function \% (n) } \\
\hline Intact & $24.3(169)$ & $21.4(149)$ & $54.2(377)$ & \multirow[t]{2}{*}{0.709} \\
\hline Impaired & $22.1(59)$ & $23.2(62)$ & $54.7(146)$ & \\
\hline \multicolumn{5}{|c|}{ Dyslipidaemia \% (n) } \\
\hline No & $29.6(45)$ & $23.0(35)$ & $47.4(72)$ & \multirow[t]{2}{*}{0.142} \\
\hline Yes & $23.2(218)$ & $21.5(202)$ & $55.3(520)$ & \\
\hline \multicolumn{5}{|c|}{ Hypertension \% (n) } \\
\hline No & $22.8(74)$ & $20.3(66)$ & $56.9(185)$ & \multirow[t]{2}{*}{0.503} \\
\hline Yes & $24.6(189)$ & $22.3(171)$ & $53.1(407)$ & \\
\hline \multicolumn{5}{|c|}{ Macrovascular complications } \\
\hline No & $25.3(199)$ & $23.1(182)$ & $51.6(406)$ & \multirow[t]{2}{*}{0.019} \\
\hline Yes & $21.0(64)$ & $18.0(55)$ & $61.0(186)$ & \\
\hline \multicolumn{5}{|c|}{ Microvascular complication } \\
\hline No & $29.4(146)$ & $23.7(118)$ & $46.9(233)$ & \multirow[t]{2}{*}{$<0.001$} \\
\hline Yes & 19.7 (117) & 20.0 (119) & 60.3 (359) & \\
\hline
\end{tabular}

inadequate and very poor glycaemic control. Similarly, more than two-thirds of participants (70.5\%) did not achieve the recommended length of time of physical activity per week even though walking for transportation and physical activities at work were included in measuring it. Results of this current study also showed that a low level of physical activity was an independent risk factor for inadequate and very poor glycaemic control. Continuous education programs emphasising the role of lifestyle modification in controlling blood glucose level will be of great benefit for people with T2DM in Saudi Arabia.

Previous studies have shown that the more knowledge of diabetes a person has the more likely that he or she will have lower HbA1c level $[17,46]$. Though the participants' knowledge of the disease was not evaluated in this study, their awareness of $\mathrm{HbA} 1 \mathrm{c}$ and its recommended level for people with diabetes was assessed as a proxy for knowledge of the disease. Only $31.9 \%$ of participants were aware of $\mathrm{HbA1c}$ and knew the recommended target $(<53 \mathrm{mmol} / \mathrm{mol}(<7 \%))$. The remaining participants either have not heard of HbA1c before $(32.0 \%)$ or did not know the recommended HbA1c target (36.1\%), which was associated with increased risk of inadequate and very poor control after adjustment for other risk factors. This finding is supported by the results of randomised control trials which showed that knowledge of actual and target HbA1c was associated with a significant reduction in HbA1c levels [47, 48]. In order to improve glycaemic control, physicians and health educators should ensure that people with diabetes are fully aware of their actual as well as the target HbA1c they should achieve.

Similar to studies conducted in the Arabian Gulf $[49,50]$ and other countries $[18,51]$ we found that younger age groups ( $\leq 60$ years) were at higher risk of inadequate glycaemic control. Younger people are more likely to be affected by the change in lifestyle and less likely to be adherent to a management plan because of active occupational and social life [52]. Old people, in contrast, are less likely to be affected by the change in lifestyle and more likely to adhere to a management plan because they might be more concerned about their health, especially when they start to have comorbidities and complications [49]. Because of the beneficial effect of optimal glycaemic control on delaying complications, improving quality of life, and extending life expectancy among young 


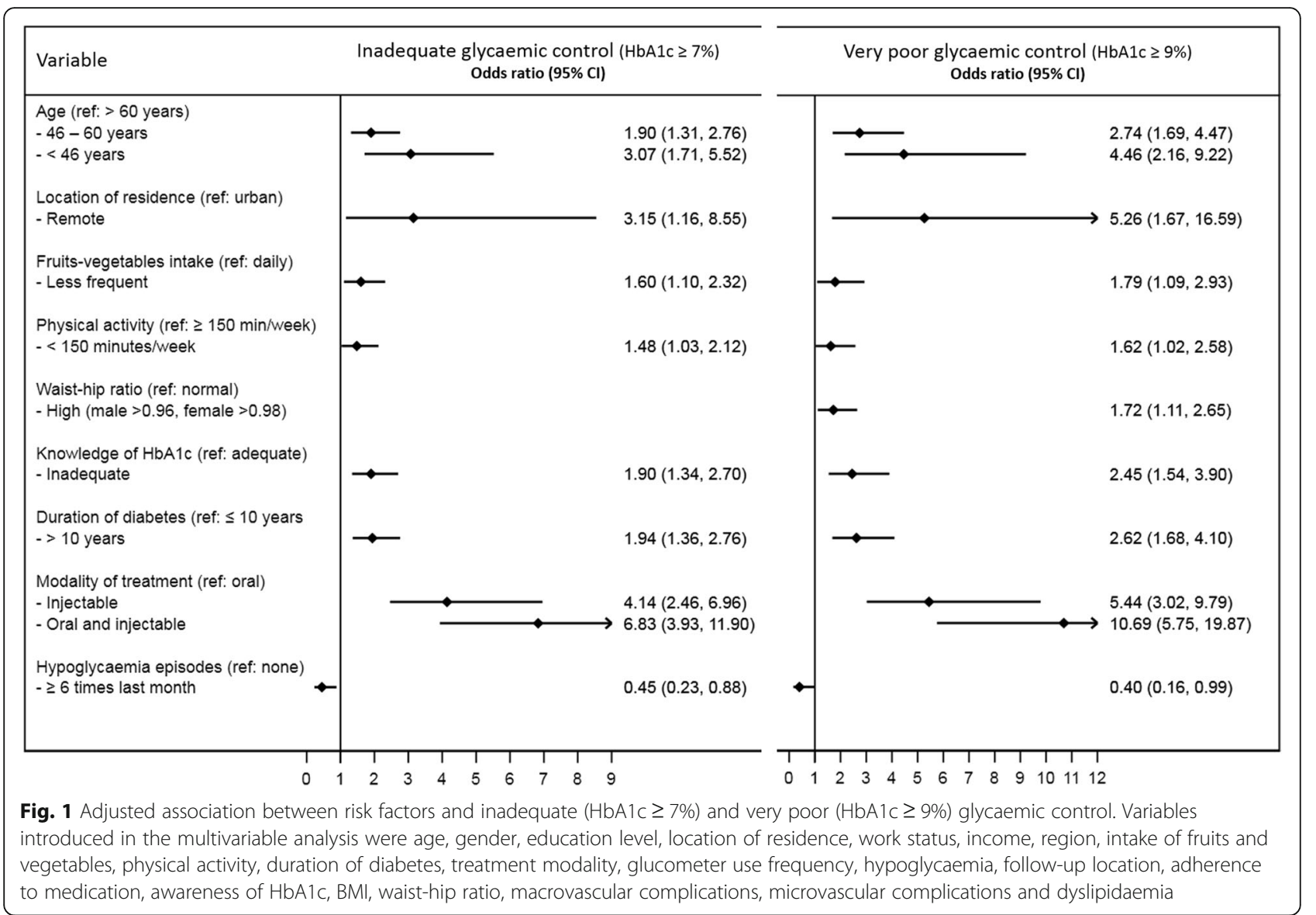

people with diabetes [53], the management should aim at tight control once the diagnosis is made.

Another concerning finding of this study is that while the mean age of participants was $57.6( \pm 11.1)$ years (median: 57.8, 25th percentile: 51.8, 75th percentile: 63.9 years), they have a relatively long mean duration of diabetes of $13.9( \pm 8.4)$ years (median: 13.0, 25th percentile: 6.0 , 75th percentile: 20 years). This indicates that the majority of people acquired diabetes in their early 40s. Early onset T2DM is associated with poor glycaemic control and a higher risk of comorbidities and complications [54]. With longer duration of T2DM, on the other hand, there is usually further deterioration of the function of the pancreas and the body's resistance to insulin increases, which makes it more difficult to control blood glucose level. The likelihood of acquiring diabetes complications also increases with longer duration, and complications can negatively affect the control either directly through inflammation and disturbance of the body's metabolism and indirectly through the effect of poly-pharmacy, anxiety, depression and stress. To prevent or delay diabetes and its complications, the healthcare system in Saudi Arabia should fully activate the screening programs and establish an intensive management protocols to identify and treat people at risk of diabetes.

Though BMI did not appear to affect glycaemic control, we found that a high waist-hip ratio was an independent risk factor for inadequate and very poor control. Similar findings were also observed in studies from Japan and the United States $[55,56]$. In addition, compared to BMI, a high waist-hip ratio was found to have stronger association with cardiovascular disease among people with type 2 diabetes [57]. Waist-hip ratio is a more accurate measure of central obesity which is strongly linked with T2DM, poor glycaemic control, and cardiovascular disease [58]. Therefore, similar to BMI, waist-hip ratio should be measured and recorded for people with diabetes with every follow up visit, and health care providers should raise the awareness of people with diabetes about high waist-hip ratio and the risk associated with it.

We found that living in a remote village was a strong predictor of inadequate and very poor glycaemic control. People living in remote villages are likely to have a low level of formal education and are likely to have less access to fresh healthy food options. Because of accessibility issues, they limit their follow-up to the local primary health care centre and may not visit a specialised diabetes clinic 


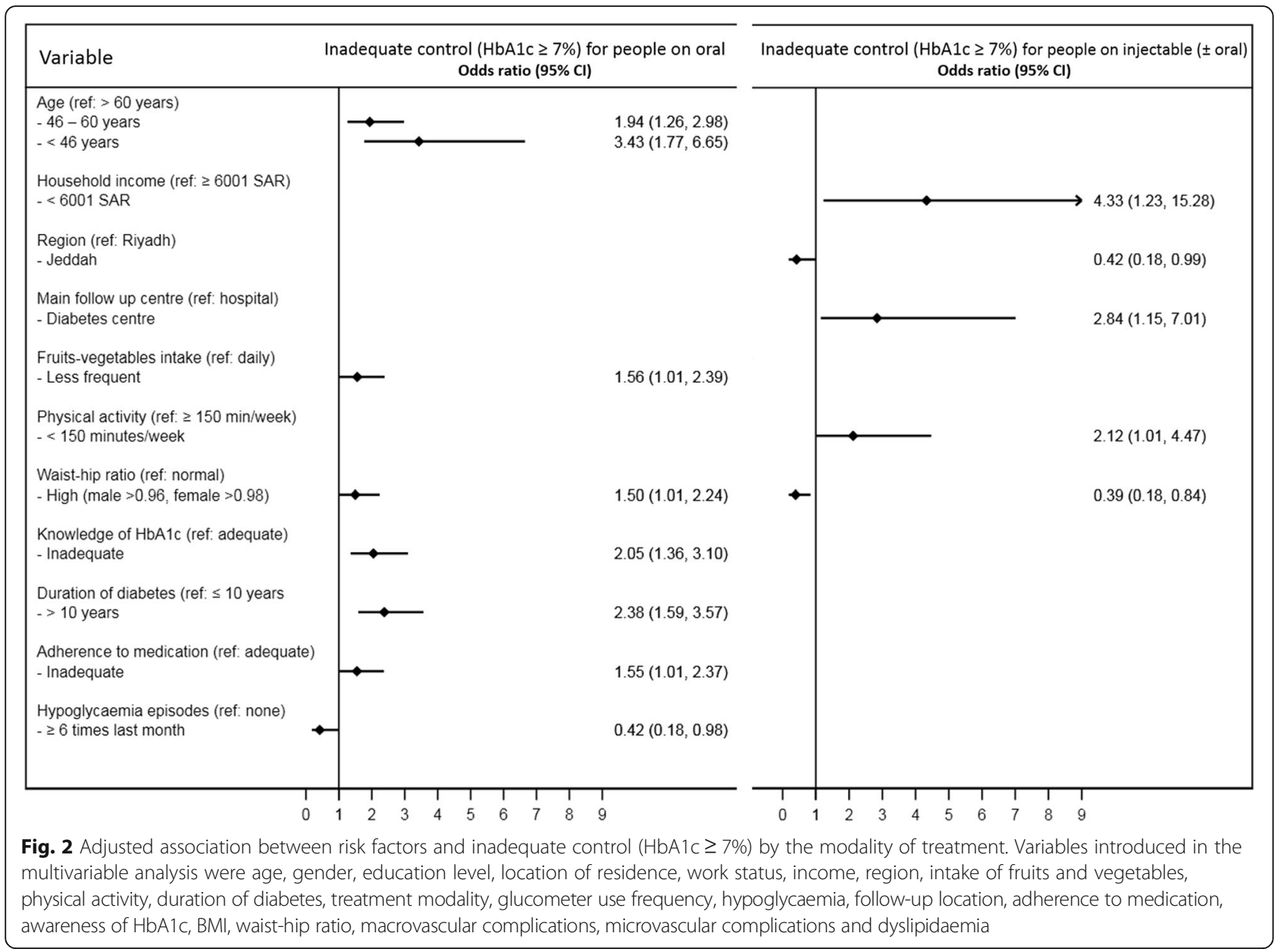

or centre until the disease has progressed and they acquire complications. To improve the control among this susceptible group, the healthcare system should provide special diabetes education programs for healthcare providers working at remote places, and motivate them to use the online continuous education programs that are currently available and accredited by the Saudi Health System. General physicians working on remote sittings should also be provided with timely hotline or email access to specialists including endocrinologists, ophthalmologist and podiatrist. Patients, on the other hand, should have frequent teleconference or phone calls by diabetes educators, dietitians and other allied health professionals if these healthcare professionals are not assigned to the remote place where patients live.

Similar to other previous studies $[18,49,50]$, our results showed that the use of injectable medications was a strong predictor for inadequate control. It is of concern that even after management with insulin, which is highly effective modality of treatment [59], a large proportion of people continued to have high blood glucose level. Low adherence to injectable medication regimen because of social stigmata, interference with daily activity, and fear of hypoglycaemia, have been suggested to increase the risk of poor control among people using injectable medications [60]. In Addition, the progression of the disease, weight gain related to insulin use, and polypharmacy can also contribute to poor glycaemic control among people with T2DM who are on injectable medications [61].

Our findings support the previous study that showed an association between inadequate glycaemic control and low income as well as low adherence to medications $[18,52,62]$. Low income decreases the likelihood of adherence to lifestyle modifications and treatment regimen [62], and low adherence to management plan is a known risk factors for poor glycaemic control [18, 52].

The association between hypoglycaemia and glycaemic control is of interest. Our findings showed that people with infrequent symptoms of hypoglycaemia were at higher risk of poor glycaemic control compared to those who had frequent symptoms of hypoglycaemic. This may indicate that while an intensive treatment regimen improve glycaemic control, it may come at the cost of frequent hypoglycaemia symptoms. Severe hypoglycaemia is associated with lower productivity, reduced quality of life, and a higher risk of anxiety, depression and mortality [63, 64]. Therefore, 
hypoglycaemia should be prevented, and the treatment should aim at achieving the lowest HbA1c level without severe hypoglycaemia episodes and a minimum number of mild hypoglycaemia symptoms [65].

The strength of this study lays on the relatively large sample size that was recruited from multiple centres from different regions of Saudi Arabia. The consideration of several potential risk factors and the use of a validated electronic questionnaire, which reduce data errors, also add strength to this study. This study, however, has some limitations. Cross-sectional study design lack temporality and causality cannot be inferred. Another limitation is that information regarding individualised glycaemic control targets could not be collected because it was not documented in participants' medical records. Therefore, a HbA1c cut off point of $7 \%$ was selected to categorise adequate control which is too strict for old people with longer duration of the disease and those who have advanced cardiovascular disease [4]. In addition, we could not investigate the effect of new anti-hyperglycaemic agents such as the glucagon-like peptide-1 (GLP-1) receptor agonists on glycaemic control because only a very small number of participants in our database were using them. Nonetheless, this study clearly revealed the burden of inadequate glycaemic control among people with T2DM in Saudi Arabia and its associated risk factors.

\section{Conclusion}

Inadequate glycaemic control is a common and widespread problem among people with T2DM in Saudi Arabia. Healthcare providers should undertake a patient-centred approach and individualise management strategies with consideration to all identified risk factors for inadequate control. Continuous education programs should also be implemented to raise the awareness of the disease and the importance of lifestyle modification. The healthcare system should prioritise diabetes prevention strategies through active screening and intensive management of people at risk. The health system should also take special measures to improve glycaemic control for people with diabetes living at remote locations. Future research should investigate the effectiveness of education programs targeting people with diabetes and barriers to adhering to lifestyle modifications.

\section{Abbreviations}

BMI: Body Mass Index; eGFR: Estimated glomerular filtration rate; HbA1c: Glycated haemoglobin A1c; HDL: High density lipoprotein; LDL: Low density lipoprotein; T2DM: Type 2 diabetes mellitus

\section{Acknowledgements}

We would like to acknowledge the contribution of Fatema A. AlRamadan, Basmah J. Al Ramadhan, Ameera J. Alramadan, Ahmed J. Alramadhan, Talal A. Alzahrani, Hawra H. Alramadhan, Ayat S. Alabdullah, Noor A. Alabdullah, Husam M. Almaramhi, Nawaf F. Almukaibil, Nouf A. Alzaid, Nour A. Bayaseh, Sara M. Alameer, Wed A. Alkharras, Ghada M Amin, and Ahmad Alhammad in the data collection for this study.

\section{Author contributions}

All authors were involved in the conception and design of the study. MJA, HJA, WFM, and AMA contributed to the acquisition of data. MJA, DJM, AA, $B B, T H A$ and $M A B$ contributed to data analysis and interpretation of results. MJA and BB drafted the manuscript. All authors critically reviewed the manuscript and approved the final version.

\section{Funding}

This research did not receive any specific grant from funding agencies in the public, commercial, or not-for-profit sectors.

\section{Availability of data and materials}

The datasets generated during and analysed during the current study are available from the corresponding author on reasonable request.

Ethics approval and consent to participate

Ethical approval was obtained from the Monash University Human Research Ethics Committee in Australia and the Research Ethics Committee of the Ministry of Health in Saudi Arabia. Written informed consent was obtained from all the study participants.

\section{Consent for publication}

Not applicable

\section{Competing interests}

The authors declare that they have no competing interests.

\section{Publisher's Note}

Springer Nature remains neutral with regard to jurisdictional claims in published maps and institutional affiliations.

\section{Author details}

${ }^{1}$ Department of Epidemiology and Preventive Medicine, School of Public Health and Preventive Medicine, Monash University, Melbourne, Australia. ${ }^{2}$ Baker Heart and Diabetes Institute, Melbourne, VIC, Australia. ${ }^{3}$ College of Medicine, King Saud University, Riyadh, Saudi Arabia. ${ }^{4}$ College of Medicine, King Faisal University, Al-Ahsa, Saudi Arabia. ${ }^{5}$ Ibn Sina National College, Jeddah, Saudi Arabia. ${ }^{6}$ Medical City - King Saud University, Riyadh, Saudi Arabia.

Received: 25 April 2018 Accepted: 29 August 2018

Published online: 10 September 2018

References

1. El Bcheraoui C, Basulaiman M, Tuffaha M, Daoud F, Robinson M, Jaber S, et al. Status of the diabetes epidemic in the Kingdom of Saudi Arabia, 2013. Int J Pub Health. 2014;59(6):1011-21.

2. Cho NH, Kirigia J, Mbanya JC, Ogurstova K, Guariguata L, Rathmann W, et al. IDF DIABETES ATLAS eighth edition 2017. Int Diabet Fed. 2017:1-147.

3. Al-Quwaidhi AJ, Pearce MS, Sobngwi E, Critchley JA, O'Flaherty M. Comparison of type 2 diabetes prevalence estimates in Saudi Arabia from a validated Markov model against the international diabetes federation and other modelling studies. Diabetes Res Clin Pract. 2014;103(3):496-503.

4. American Diabetes Association. American Diabetes Association Standards of Medical Care in Diabetes-2017. The Journal of Clinical and Applied Research and Education. 2017;40.

5. Collaboration ERF. Diabetes mellitus, fasting glucose, and risk of cause-specific death. N Engl J Med. 2011;2011(364):829-41.

6. Klein R, Klein BE, Moss SE. Relation of glycemic control to diabetic microvascular complications in diabetes mellitus. Ann Intern Med. 1996; 124(1_Part_2):90-6.

7. Ismail-Beigi F, Craven T, Banerji MA, Basile J, Calles J, Cohen RM, et al. Effect of intensive treatment of hyperglycaemia on microvascular outcomes in type 2 diabetes: an analysis of the ACCORD randomised trial. Lancet. 2010; 376(9739):419-30.

8. Duckworth W, Abraira C, Moritz T, Reda D, Emanuele N, Reaven PD, et al. Glucose control and vascular complications in veterans with type 2 diabetes. N Engl J Med. 2009;360(2):129-39.

9. Al-Nuaim AR, Mirdad S, Al-Rubeaan K, Al-Mazrou Y, Al-Attas O, Al-Daghari N. Pattern and factors associated with glycemic control of Saudi diabetic patients. Ann Saudi Med. 1998;18(2):109-12. 
10. Al-Hayek AA, Robert AA, Alzaid AA, Nusair HM, Zbaidi NS, Al-Eithan MH, et al. Association between diabetes self-care, medication adherence, anxiety, depression, and glycemic control in type 2 diabetes. Saudi Med J. 2012; 33(6):681-3.

11. Alsulaiman TA, Al-Ajmi HA, Al-Qahtani SM, Fadlallah IM, Nawar NE, Shukerallah RE, et al. Control of type 2 diabetes in king Abdulaziz Housing City (Iskan) population, Saudi Arabia. J Family Community Med. 2016;23(1):1.

12. Almutairi MA, Said SM, Zainuddin H. Predictors of poor glycemic control among type two diabetic patients. Am J Med Medical Sci. 2013;3(2):17-21.

13. Alzaheb RA, Altemani AH. The prevalence and determinants of poor glycemic control among adults with type 2 diabetes mellitus in Saudi Arabia. Diabetes Metab Syndr Obes. 2018;11:15.

14. Alwakeel J, Sulimani R, Al-Asaad H, Al-Harbi A, Tarif N, Al-Suwaida A, et al. Diabetes complications in 1952 type 2 diabetes mellitus patients managed in a single institution. Ann Saudi Med. 2008;28(4):260.

15. Al Ghamdi AH, Rabiu M, Hajar S, Yorston D, Kuper H, Polack S. Rapid assessment of avoidable blindness and diabetic retinopathy in Taif, Saudi Arabia. Br J Ophthalmol. 2012;96(9):1168-72.

16. Halawa MR, Karawagh A, Zeidan A, Mahmoud A-E-DH, Sakr M, Hegazy A. Prevalence of painful diabetic peripheral neuropathy among patients suffering from diabetes mellitus in Saudi Arabia. Curr Med Res Opin. 2010; 26(2):337-43.

17. Binhemd TA. Diabetes mellitus: knowledge, attitude, practice and their relation to diabetes control in female diabetics. Ann Saudi Med. 1992; 12(3):247-51.

18. Sanal T, Nair N, Adhikari P. Factors associated with poor control of type 2 diabetes mellitus: a systematic review and meta-analysis. J Diabetol. 2011; $3(1): 1-10$.

19. Alramadan MJ, Afroz A, Batais MA, Almigbal TH, Alhamrani HA, Albaloshi A et al. A study protocol to assess the determinants of Glycaemic control, complications and health related quality of life for people with type 2 diabetes in Saudi Arabia. J Health Edu Res Develop. 2017;5(2):1-6.

20. Al-Turki YA. Blood sugar control, ophthalmology referral and creatinine leve among adult diabetic patients in primary health care, Riyadh, Saudi Arabia. Saudi Med J. 2002:23(11):1332-4.

21. Harris PA, Taylor R, Thielke R, Payne J, Gonzalez N, Conde JG. Research electronic data capture (REDCap) — a metadata-driven methodology and workflow process for providing translational research informatics support. J Biomed Inform. 2009;42(2):377-81.

22. Armstrong T, Bull F. Development of the world health organization global physical activity questionnaire (GPAQ). J Public Health. 2006;14(2):66-70.

23. England CY, Thompson JL, Jago R, Cooper AR, Andrews RC. Development of a brief, reliable and valid diet assessment tool for impaired glucose tolerance and diabetes: the UK diabetes and diet questionnaire. Public Health Nutr. 2017;20(2):191-9.

24. Morisky DE, Green LW, Levine DM. Concurrent and predictive validity of a selfreported measure of medication adherence. Med Care. 1986;24(1):67-74.

25. Moghtaderi A, Bakhshipour A, Rashidi H. Validation of Michigan neuropathy screening instrument for diabetic peripheral neuropathy. Clin Neurol Neurosurg. 2006;108(5):477-81.

26. Skapinakis P. The 2-item Generalized Anxiety Disorder scale had high sensitivity and specificity for detecting GAD in primary care. Evid Based Med. 2007:12(5):149

27. Kroenke K, Spitzer RL, Williams JB. The patient health Questionnaire-2: validity of a two-item depression screener. Med Care. 2003;41(11):1284-92.

28. Storey JE, Rowland JT, Conforti DA, Dickson HG. The Rowland universal dementia assessment scale (RUDAS): a multicultural cognitive assessment scale. Int Psychogeriatr. 2004;16(01):13-31.

29. Oglesby AK, Secnik K, Barron J, Al-Zakwani I, Lage MJ. The association between diabetes related medical costs and glycemic control: a retrospective analysis. Cost Eff Resour Alloc. 2006;4(1):1.

30. Al-Lawati JA, Barakat NM, Al-Lawati AM, Mohammed AJ. Optimal cut-points for body mass index, waist circumference and waist-to-hip ratio using the Framingham coronary heart disease risk score in an Arab population of the Middle East. Diab Vasc Dis Res. 2008;5(4):304-9.

31. Deed G, Ackermann E, Newman R, Audehm R, Arthur I, Barlow J, et al. General Practice Management of Type 2 Diabetes: 2014-15: Royal Australian College of General Practitioners (RACGP); 2014

32. Levey AS, Stevens LA, Schmid CH, Zhang YL, Castro AF, Feldman HI, et al. A new equation to estimate glomerular filtration rate. Ann Intern Med. 2009; 150(9):604-12
33. Grams ME, Rebholz CM, McMahon B, Whelton S, Ballew SH, Selvin E, et al. Identification of incident CKD stage 3 in research studies. Am J Kidney Dis. 2014;64(2):214-21

34. Billah B, Huq MM, Smith JA, Sufi F, Tran L, Shardey GC, et al. AusSCORE II in predicting 30-day mortality after isolated coronary artery bypass grafting in Australia and New Zealand. J Thorac Cardiovasc Surg. 2014;148(5):1850-5. e2

35. Al Baghli N, Al Turki K, Al Ghamdi A, El Zubaier A, Al Ameer M, Al Baghli F. Control of diabetes mellitus in the eastern province of Saudi Arabia: results of screening campaign. 2010.

36. Al-Rasheedi AAS. The role of educational level in glycemic control among patients with type II diabetes mellitus. Int J Health Sci. 2014;8(2):177.

37. Al Balushi KA, Al-Haddabi M, Al-Zakwani I, Al Z'a M. Glycemic control among patients with type 2 diabetes at a primary health care center in Oman. Prim Care Diabetes. 2014;8(3):239-43.

38. Al-Ibrahim AAH. Factors associated with compliance to diabetes selfcare behaviors and glycemic control among Kuwaiti people with type 2 diabetes 2012.

39. Al-Kaabi J, Al-Maskari F, Saadi H, Afandi B, Parkar H, Nagelkerke N. Assessment of dietary practice among diabetic patients in the United Arab Emirates. Rev Diabet Stud. 2008;5(2):110-5.

40. Al-Hamdan N, Kutbi A, Choudhry A, Nooh R, Shoukri M, Mujib S. WHO stepwise approach to NCD surveillance country-specific standard report Saudi Arabia. In: Organization WH, editor. WHO Stepwise Approach. Geneva: WHO; 2005.

41. Al-Nozha MM, Al-Hazzaa HM, Arafah MR, Al-Khadra A, Al-Mazrou YY, Al-Maatouq MA, et al. Prevalence of physical activity and inactivity among Saudis aged 30-70 years. A population-based cross-sectional study. Saudi Med J. 2007;28(4):559-68.

42. Al Othaimeen A, Al Nozha M, Osman A. Obesity: an emerging problem in Saudi Arabia. Analysis of data from the National Nutrition Survey. East Mediterr Health J. 2007;13(2):441-8.

43. Al-Nozha MM, Al-Maatouq MA, Al-Mazrou YY, Al-Harthi SS, Arafah MR, Khalil MZ, et al. Diabetes mellitus in Saudi Arabia. Saudi Med J. 2004;25(11):1603-10.

44. Alqurashi K, Aljabri K, Bokhari S. Prevalence of diabetes mellitus in a Saudi community. Ann Saudi Med. 2011;31(1):19.

45. Shamsi N, Shehab Z, AlNahash Z, AlMuhanadi S, Al-Nasir F. Factors influencing dietary practice among type 2 diabetics. Bahrain Med Bull. 2013:35:3.

46. Tang YH, Pang S, Chan MF, Yeung GS, Yeung VT. Health literacy, complication awareness, and diabetic control in patients with type 2 diabetes mellitus. J Adv Nurs. 2008;62(1):74-83.

47. Cagliero E, Levina EV, Nathan DM. Immediate feedback of HbA1c levels improves glycemic control in type 1 and insulin-treated type 2 diabetic patients. Diabetes Care. 1999;22(11):1785-9.

48. Levetan CS, Dawn KR, Robbins DC, Ratner RE. Impact of computergenerated personalized goals on HbA1c. Diabetes Care. 2002;25(1):2-8.

49. Al-Lawati JA, Barakat MN, Al-Maskari M, Elsayed MK, Al-Lawati AM, Mohammed AJ. HbA1c levels among primary healthcare patients with type 2 diabetes mellitus in Oman. Oman Med J. 2012;27(6):465-70.

50. D'Souza MS, Karkada SN, Hanrahan NP, Venkatesaperumal R, Amirtharaj A. Do perceptions of empowerment affect glycemic control and self-care among adults with type 2 diabetes? Glob J Health Sci. 2015;7(5):80-90.

51. McBrien K, Manns B, Hemmelgarn B, Weaver R, Edwards A, Ivers $N$, et al. The association between sociodemographic and clinical characteristics and poor glycaemic control: a longitudinal cohort study. Diabet Med. 2016;33(11):1499-507.

52. Alramadan MJ, Afroz A, Hussain SM, Batais MA, Almigbal TH, Al-Humrani HA et al. Patient-related determinants of Glycaemic control in people with type 2 diabetes in the Gulf cooperation council countries: a systematic review. J Diabet Res. 2018;2018:9389265.

53. Drewelow E, Wollny A, Pentzek M, Immecke J, Lambrecht S, Wilm S, et al. Improvement of primary health care of patients with poorly regulated diabetes mellitus type 2 using shared decision-making-the DEBATE trial. BMC Fam Pract. 2012;13(1):88.

54. Chuang L-M, Soegondo S, Soewondo P, Young-Seol K, Mohamed M, Dalisay $E$, et al. Comparisons of the outcomes on control, type of management and complications status in early onset and late onset type 2 diabetes in Asia. Diabetes Res Clin Pract. 2006;71(2):146-55.

55. Hsieh $\mathrm{S}$, Yoshinaga $\mathrm{H}$. Abdominal fat distribution and coronary heart disease risk factors in men-waist/height ratio as a simple and useful predictor. Int J Obes Relat Metab Disord. 1995;19(8):585-9.

56. Eberhardt MS, Lackland DT, Wheeler FC, German RR, Teutsch SM. Is race related to glycemic control? An assessment of glycosylated hemoglobin in two South Carolina communities. J Clin Epidemiol. 1994;47(10):1181-9. 
57. Czernichow S, Kengne A-P, Huxley RR, Batty GD, De Galan B, Grobbee D, et al. Comparison of waist-to-hip ratio and other obesity indices as predictors of cardiovascular disease risk in people with type-2 diabetes: a prospective cohort study from ADVANCE. Eur J Cardiovasc Prev Rehabil. 2011;18(2):312-9.

58. Astrup A, Finer N. Redefining type 2 diabetes:'diabesity'or 'obesity dependent diabetes mellitus'? Obes Rev. 2000;1 (2):57-9.

59. Nathan DM, Buse JB, Davidson MB, Ferrannini E, Holman RR, Sherwin R, et al. Medical management of hyperglycemia in type 2 diabetes: a consensus algorithm for the initiation and adjustment of therapy: a consensus statement of the American Diabetes Association and the European Association for the Study of diabetes. Diabetes Care. 2009; 32(1):193-203.

60. Peyrot M, Barnett A, Meneghini L, Schumm-Draeger PM. Insulin adherence behaviours and barriers in the multinational global attitudes of patients and physicians in insulin therapy study. Diabet Med. 2012;29(5):682-9.

61. Davies $\mathrm{M}$. The reality of glycaemic control in insulin treated diabetes: defining the clinical challenges. Int J Obes. 2004;28:S14-22.

62. Brown AF, Ettner SL, Piette J, Weinberger M, Gregg E, Shapiro MF, et al. Socioeconomic position and health among persons with diabetes mellitus: a conceptual framework and review of the literature. Epidemiol Rev. 2004; 26(1):63-77.

63. Davis RE, Morrissey M, Peters JR, Wittrup-Jensen K, Kennedy-Martin T, Currie CJ. Impact of hypoglycaemia on quality of life and productivity in type 1 and type 2 diabetes. Curr Med Res Opin. 2005;21(9):1477-83.

64. Bonds DE, Miller ME, Bergenstal RM, Buse JB, Byington RP, Cutler JA, et al. The association between symptomatic, severe hypoglycaemia and mortality in type 2 diabetes: retrospective epidemiological analysis of the ACCORD study. BMJ. 2010;340:b4909.

65. Seaquist ER, Anderson J, Childs B, Cryer P, Dagogo-Jack S, Fish L, et al. Hypoglycemia and diabetes: a report of a workgroup of the American Diabetes Association and the Endocrine Society. J Clin Endocrinol Metabol. 2013;98(5):1845-59.

Ready to submit your research? Choose BMC and benefit from:

- fast, convenient online submission

- thorough peer review by experienced researchers in your field

- rapid publication on acceptance

- support for research data, including large and complex data types

- gold Open Access which fosters wider collaboration and increased citations

- maximum visibility for your research: over $100 \mathrm{M}$ website views per year

At $\mathrm{BMC}$, research is always in progress.

Learn more biomedcentral.com/submissions 